\title{
ON AN 'UNINTELLIGIBLE' IDEA: DONALD DAVIDSON'S CASE AGAINST EXPERIENTIAL FOUNDATIONALISM
}

\author{
Southern Journal of Philosophy, forthcoming \\ Daniel Howard-Snyder \\ Dept. of Philosophy \\ Western Washington University \\ Bellingham, WA 98225
}

\begin{abstract}
Donald Davidson's epistemology is predicated on, among other things, the rejection of Experiential Foundationalism, which he calls 'unintelligible'. In this essay, I assess Davidson's arguments for this conclusion. I conclude that each of them fails on the basis of reasons that foundationalists and antifoundationalists alike can, and should, accept.
\end{abstract}

A particular belief of a person is basic just in case it is epistemically justified and it owes its justification to something other than her other justified beliefs or their interrelations; a person's belief is nonbasic just in case it is epistemically justified but not basic. Foundationalists agree that if one has a nonbasic belief, then — at rock bottom - it owes its justification to at least one basic belief. There are justified beliefs because and only because there are basic beliefs. Such is the genus Foundationalism. One species is Experiential Foundationalism, the view that a basic belief can owe its justification to experience. ${ }^{1}$

Donald Davidson rejects Experiential Foundationalism. Experience, he says, cannot be a 'reason' or, more generally, an 'epistemological basis' or 'ground or source of justification' of a belief; indeed, the very idea of experience justifying belief is 'unintelligible,' according to Davidson. In this essay, I assess his arguments for this conclusion.

Three stage-setting remarks are in order. First, most critics of Foundationalism - including Davidson - are not skeptics. Indeed, one frequently hears that because Foundationalism implies skepticism, it should be rejected. As it turns out, however, many of the epistemic principles that Davidson relies on in his attack on Experiential Foundationalism have radically skeptical implications. In what follows, I will assume without argument that these implications suffice to reject those principles. Second, Davidson says that he concludes that the very idea of experience justifying belief is 'unintelligible,' but he can't mean that. That's because his reasons for rejecting Experiential Foundationalism take the form 'If experience could justify belief, then...,' where the consequent specifies what he regards as a logical implication of the antecedent. One can no more say that experience's justifying belief is unintelligible and has certain logical implications than one can say that the sentence 'Twas brillig and the slithy toves did jire and gimble in the wabe' is unintelligible but has certain logical implications. Of course, something can be impossible, even if, strictly speaking, it is intelli-

\footnotetext{
${ }^{1}$ Two clarifications are in order. First, although I have characterized Foundationalism in terms of epistemic justification, it is not wedded to that family of concepts. Substitute whatever general terms of epistemic appraisal you like and the foundationalist will offer you a basic/nonbasic distinction. Since 'justification' is, apparently, Davidson's preferred term, I'll stick with it. Second, experiential foundationalists are sometimes accused of denying the obvious fact that a belief's justification can have multiple sources. For example, suppose I believe with justification the twins are crying, and my belief owes its justification to (i) my present auditory experience as well as (ii) an inference from the present testimony of my wife. Is my belief basic or nonbasic? I think the foundationalist should say that it all depends. If, all else being equal, my belief would still be justified even if it did not owe its justification to my inference from my wife's testimony, then it is basic; if it would not, then it is nonbasic.
} 
gible. This is how I shall understand Davidson's conclusion. Third, great philosophers, like the common run of humanity, have a difficult time saying exactly what they mean, and Davidson is no exception. We are left with no hermeneutical alternative, therefore, but to reconstruct and evaluate several arguments suggested by the text, in the hope that at least some of them were intended by him.

\section{The 'Justification is not Causation' Objection}

The first argument I wish to consider can be found in this oft-cited passage ${ }^{2}$ :

The relation between a sensation and a belief cannot be logical, since sensations are not beliefs or other propositional attitudes. What then is the relation? The answer is, I think, obvious: the relation is causal. Sensations cause some beliefs and in this sense are the basis or ground of those beliefs. But a causal explanation of a belief does not show how or why the belief is justified. (311)

Although Davidson is thinking here in terms of 'sensations,' his intended target is any "attempt to ground belief in one way or another on the testimony of the senses: sensation, perception, the given, experience, sense data, the passing show" (310). Since 'experience' is the most general term for that of which he speaks, it is the term I will use in my reconstructions of his arguments.

With that in mind, what exactly is the argument of the passage? At first blush, one might think it is this:

1. The relation between an experience and a belief is causal.

2. A causal explanation of a belief does not show how or why the belief is justified.

3. So, an experience cannot justify a belief. $(1,2)$

Unfortunately, this argument is obviously logically invalid. We can correct this defect in one of two ways. First, we can regard the premises as necessarily true, if true at all; second, we can regard the conclusion as contingently true, if true at all. The text does not support the second option. That's because Davidson is engaged in nothing but a bit of old-fashioned $a$ priori armchair philosophizing, never mind how he'd (mis)characterize it. So I choose the first option. Now, as it turns out, all of Davidson's arguments fall to this objection; sensitivity to modal matters isn't his strong suit. Thus, to avoid needless repetition, I will reconstruct each of his arguments accordingly.

So, we have this argument:

1. Necessarily, the relation between an experience and a belief is causal.

2. Necessarily, a causal explanation of a belief does not show how or why the belief is justified.

3. So, an experience cannot justify a belief. $(1,2)$

What should we make of this line of reasoning?

If we understand premise 1 as the claim that, necessarily, the only relation between an experience and a belief is causal, then it is false. Non-causal relations between experience and belief are a dime a dozen. However, if we understand premise 1 as the claim that, necessarily, one among many relations between an experience and a belief is the causal relation, then

\footnotetext{
2 "A Coherence Theory of Truth and Knowledge," in ed. Ernest Lepore, Truth and Interpretation: Perspectives on the Philosophy of Donald Davidson (Oxford: Blackwell, 1986), 307-19. Unless otherwise stated, all page references in the text are to this work. This essay was first published in ed. Dieter Henrich, Kant oder Hegel (Stuttgart: Klett Cotta, 1983), 423-38.
} 
the argument is a non-sequitur. There is no other way to understand premise 1; either way, then, the argument is unsound.

Perhaps a bit more of an informal explanation of my objection is in order. No one doubts that the mere fact that an experience causes a belief cannot be the whole explanation of how and why the belief is justified. But no experiential foundationalist ever said it was. Rather, according to the experiential foundationalist, a belief owes its justification to an experience that caused it only if other non-causal facts and relations obtain. As you might expect, experiential foundationalists differ over what those other non-causal facts and relations are, but it is a well-known fact - apparently disregarded by Davidson - that they are a part of every experiential foundationalist's story. Some popular options, which are not (all) mutually exclusive, include these: an experience can justify one's belief only if...

- ...it's not possible to have that experience whilst the belief is false;

- ...one would not have the experience unless the belief were true;

- ...the experience makes the belief that arises from it very likely to be true;

- ...the experience is the input of a reliable belief-forming process;

- ...one is non-negligently unaware of any good reason to think the experience is not truth-conducive, or that the belief based on it is false;

- ...one has not violated any epistemic duty in believing on the basis of that experience;

- ...the best explanation of one's having that experience is that the belief is true.

- ...the experience is evidence for the belief.

- ...the experience is the input of properly functioning cognitive capacities that are aimed at truth and reliable in the environments for which they were designed.

- ...one is immediately aware of (or, directly acquainted with) certain aspects of or facts about the experience.

And there are other options besides, as well as variations on those mentioned here.

The upshot, then, is this: even if a causal explanation by itself does not show how or why a belief is justified on the basis of an experience, an experience may nevertheless be an indispensable component of an epistemologically robust explanation of how or why a belief is justified — which is what experiential foundationalists have said all along.

\section{The 'Experience Can't Confirm' Objection}

Perhaps I have misunderstood the passage quoted above. Perhaps Davidson meant to emphasize the fact that the relation between an experience and a belief is not logical rather than that it is causal. We can bring this emphasis in the passage to light if we pursue several questions.

\subsection{The experience-lacks-propositional-content version}

First, what is the point of saying that "The relation between a sensation and a belief cannot be logical, since sensations are not beliefs or other propositional attitudes"? Presumably, it is that while beliefs can enter into logical relations, sensations cannot. But how is that relevant to whether a belief can owe its justification to a sensation? Presumably, because when something renders a belief justified, the relation between the two is, at least in part, a logical relation. Consequently, if a belief could owe its justification to a sensation, a logical relation would have to obtain between them. But, says Davidson, the relation between a sensation and a belief cannot be logical. Why is that? Because "sensations are not beliefs or other propositional attitudes." It follows that a belief cannot owe its justification to a sensation. 
Davidson alludes to this line of thought elsewhere, specifying the logical relation in question as confirmation. ${ }^{3}$ Davidson's commentators, Nicholas Everitt and Eric Fisher, who endorse the argument, highlight the relation between justification and confirmation in their characterization of his argument:

If your belief that $p$ is justified by your belief that $q$, this is to say in part that $q$ confirms $p$, where what this in turn means is that the truth of $q$ increases the likelihood that $p$ is true. Justification, in other words, has been understood in terms of confirmation, and confirmation has been understood in terms of a relation holding between things (like beliefs) which can be true or false. What the [experiential] foundationalist is implicitly proposing is a notion of justification that will not fit this account.... [She] is supposing that my beliefs about external objects... are justified by the sense impressions themselves. But sense impressions cannot be true or false- they do not say anything, and hence do not say anything true or false. They just are. Because they cannot be true or false, they cannot stand in any confirmation relations to beliefs, and since we are interpreting justification in terms of confirmation it follows that sense impressions cannot act as justifiers of beliefs, not even as justifiers of beliefs about sense impressions. ${ }^{4}$

A fair way to summarize the argument, and extend it to experience in general, goes like this: 1. Necessarily, if a belief owes its justification to some other mental state, then that other state confirms the belief.

2. Necessarily, if that other state confirms the belief, then that other state is a propositional attitude.

3. Necessarily, an experience is not a propositional attitude.

4. So, necessarily, if a belief owes its justification to some other mental state, then that other state is not an experience. (1-3)

Therefore, experience cannot justify belief; so, Experiential Foundationalism is false. What should we make of this argument?

John McDowell has recently sketched an account of perceptual knowledge according to which the world is the totality of facts, and in perceptual experience one 'takes in' those facts and in belief one 'affirms' them. On this view, an experience is a sort of propositional attitude; it has propositional content. If McDowell is right, premise 3 is false. In the next section, I will assess Davidson's recent response to McDowell. Let's assume in the remainder of the present section that premise 3 is true. That is, let's assume either that experience is representational but has no propositional content, or else that it is not re-presentational at all but presentational. $^{5}$

How does Davidson's argument fare under our assumption? Not well, it turns out. To see why, let's distinguish two concepts, or families of concepts, that go under the term 'epistemic justification'. On the one hand, there is the truth-conducivity concept, according to which (roughly) justification is a matter of believing in such a way that makes it highly likely that one's belief is true. On the other hand, there is the deontological concept, according to which (roughly) justification is a matter of believing in such a way that one does not violate any of one's epistemic duties, duties illustrated by the likes of Don't believe something that

\footnotetext{
3 "Empirical Content," in Truth and Interpretation, 331.

${ }^{4}$ Modern Epistemology (New York: McGraw Hill, 1995), 84.

${ }^{5}$ As for the suggestion that experience is presentational, not re-presentational, see William Alston, "The Theory of Appearing," Philosophical Perspectives (1999), and Pierre Le Morvan, The Theory of Appearing Defended (dissertation, Syracuse University, 2000).
} 
you have just as good reason to believe is false as true, or Believe those things that are clearly likely given other things you justifiably believe, or Critically reflect on your beliefs. ${ }^{6}$ While many epistemologists insist that a belief is justified only if both concepts apply to it, many others insist that only one must, and, of these, many insist that only the deontological concept must.

Now, suppose this last group has it right; that is, suppose that a purely deontological conception of epistemic justification is correct. Then premise 1 is false, since we can refrain from violating our epistemic duties even if our beliefs are not confirmed. After all, if I'm doing the best I can to believe only on the basis of grounds that confirm my beliefs, theneven if, unbeknownst to me, I am unlucky enough to fail - I'm not rightly blamed for failing, in which case I have not violated any duty of mine. To illustrate the claim here, suppose that, unbeknownst to all of us, we are being systematically deceived by a Cartesian evil demon. In that case, the argument goes, although our grounds don't make our physical object beliefs likely to be true they are nevertheless mostly justified. ${ }^{7}$

But suppose a purely deontological conception of epistemic justification is incorrect. ${ }^{8}$ Then, epistemic justification requires truth-conducivity. In that case, however, premise 2 is false. For in the typical case, one's belief that $x$ is $F$ is more likely to be true than its denial when $\mathrm{x}$ (phenomenally) appears $\mathrm{F}$ to one. I look toward the back of the room and the wall appears smooth to me. In the circumstances, the wall's appearing smooth to me makes it much more likely than not that the wall is smooth. (Note: I did not say that the truth of the proposition that the wall appears smooth to me makes it much more likely than not that the wall is smooth, although that is true as well.) Moreover, purely qualitative states-paradigm cases of mental states that lack propositional content - can make the content of a belief more probable than its denial. My wife gives me a frisky pinch, and I feel just a bit of pain. Naturally enough, I believe that I feel pain. My feeling pain makes it exceedingly likely that my belief is true. (Note: I did not say that the truth of the proposition that I feel pain makes it exceedingly likely that my belief is true, although that is true as well.) And the same could be said about other qualitative states, e.g., itches, tickles, tastes, smells, etc., and the beliefs to which they naturally give rise.

So, Davidson faces a dilemma. Either a purely deontological conception of epistemic justification is correct or it isn't. If it is, premise 1 is false; if it isn't, premise 2 is false.

\subsection{The experience-occurs-in-our-sensory-apparatus version}

Elsewhere, Davidson presents a different rationale for thinking that experience cannot confirm belief:

[Experience] bears no epistemological fruit except as it causes us to add to, cling to, or abandon our beliefs. This causal relation cannot be a relation of confirmation or disconfirmation, since the cause is not a proposition or belief, but an event in the world or in our sensory apparatus. ${ }^{9}$

\footnotetext{
${ }^{6}$ These examples are merely illustrative. For more on the deontological/truth-conducivity divide, see Alston, "Concepts of Epistemic Justification," in Epistemic Justification (Ithaca, New York: Cornell University Press, 1989), 81114.

${ }^{7}$ Richard Foley argues for this claim forcefully in "What's Wrong with Reliabilism?," The Monist 68 (1985), 188202. My mentioning it should not be mistaken for an endorsement.

${ }^{8}$ Alternatively, suppose a purely deontological conception is correct but that we have an objective epistemic duty to believe only on the basis of truth-conducive grounds. In that case, premise 1 is true. In the previous paragraph, I assumed that we have no such objective epistemic duties. If we do, what I say in the present paragraph applies.

9 "Empirical Content," 331.
} 
The argument appears to be this:

1. Necessarily, if a belief owes its justification to some other mental state, then that other state confirms the belief.

2. Necessarily, if that other state confirms the belief, then that other state is not "an event in the world or in our sensory apparatus".

3. Necessarily, an experience is "an event in the world or in our sensory apparatus".

4. So, necessarily, if a belief owes its justification to some other mental state, then that other state is not an experience. (1-3)

What should we make of this line of thought? Of course, as before, a purely deontological conception of justification arguably implies the denial of premise 1 . But let that pass. What about premise 2 ?

On the face of it, premise 2 is quite puzzling. After all, a belief is an event in the world, and hence a belief is an "an event in the world or in our sensory apparatus". Thus, if-as premise 2 states - an experience cannot confirm a belief because it is "an event in the world or in our sensory apparatus," then a belief cannot confirm another belief for the very same reason.

Perhaps Davidson means to contrast two mutually exclusive groups of events, (i) those that occur outside our skins or in our sensory apparatus and (ii) those that occur inside our skins but not in our sensory apparatus, on the other. Beliefs fall in (ii); experiences in (i). ${ }^{10}$ Since none of our mental states occur outside our skins, the real contrast boils down to (i) events that occur in our sensory apparatus and (ii) those that do not. So the argument would be better expressed like this:

1. Necessarily, if a belief owes its justification to some other mental state, then that other state confirms the belief.

2'. Necessarily, if that other state confirms the belief, then that other state is not an event in our sensory apparatus.

3'. Necessarily, an experience is an event in our sensory apparatus.

4. So, necessarily, if a belief owes its justification to some other mental state, then that other state is not an experience. (1-3')

Premise 2' avoids my objection to premise 2, but consider premise 3 '. It immediately forces us to ask, where must experiences occur?

Of course, a substance dualist will insist that mental states in general, and experiences in particular, occur in the soul, which is not even in part constituted by our sensory apparatus. But let us suppose that we are merely material beings. Even so, why suppose experiences must occur in our sensory apparatus? Ignore the modality of the claim for the moment, and consider a simpler question: where do experiences in fact occur? Davidson says they occur in our sensory apparatus? Here's an alternative: experiences do not occur in our sensory apparatus but as a result of their operation. This latter option is countenanced by cognitive scientists who take it that typical experiences of the world involve object identification, and who insist that object identification is due in large part to long-term memory, a cognitive module they would not include in what they would call 'our sensory apparatus'. If we take cognitive science seriously, then we should say premise 3 ' is false.

One might regard this objection with suspicion. After all, one might say, Davidson's argument could just as easily be put in terms of experience resulting from processes involving

\footnotetext{
${ }^{10}$ I owe this charitable interpretation to my favorite Australian, Stuart Brock.
} 
our sensory apparatus rather than occurring in it, in which case 3' would be modified into the truth that

3'. Necessarily, an experience is an event resulting from processes involving our sensory apparatus.

Of course, premise 2' would also have to be modified, to retain a valid argument:

2''. Necessarily, if that other state confirms the belief, then that other state is not an event resulting from processes involving our sensory apparatus.

But 2', I'm sad to report, is false; a belief can confirm another belief even though it, just like an experience, is an event resulting from processes involving our sensory apparatus. Friends of Davidson might take heart, however, in the observation that experience occurs further upstream in the relevant processes than belief does. For in that case, we might replace 2" with

2 "'. Necessarily, if that other state confirms the belief, then it is not an event im-

mediately resulting from processes involving our sensory apparatus.

Alas, this premise is likewise a disappointment. It amounts to nothing more than pointing at experience on a perceptual flow chart and saying 'That can't confirm belief'. One is left wondering, 'Well, why?'

Perhaps we got off on the wrong foot here. Perhaps, 'our sensory apparatus' is - by definition - wherever experience occurs. No wonder, then, that Davidson doesn't consider what cognitive scientists say about the matter. No wonder, then, that experience must occur in our sensory apparatus. This way of affirming premise 3' comes at a steep price, however. For if our sensory apparatus is, by definition, wherever experience occurs, premise 2' comes to nothing more than the question-begging

2,",' Necessarily, if that other state confirms the belief, then it is not an experience.

Before moving on, let's return briefly to premise 2'. Why does the location of a mental state have a bearing on whether it can confirm a belief? In particular, why does being located in our sensory apparatus have this bearing? Suppose we were wired so that some beliefs occurred in our sensory apparatus. Would that render them unable to confirm beliefs that occurred outside our sensory apparatus? Of course not. Whether a belief occurred inside or outside our sensory apparatus would make no difference at all to whether it made another belief more likely to be true. But then why doesn't the same go for other mental states? As we saw at the end of section 2.1, nondoxastic states, even ones that lack content altogether, can make a belief more likely to be true than it otherwise would be. It seems, then, that even if, contrary to the deliverances of cognitive science, experience must occur in our sensory apparatus, it could still confirm belief.

I conclude that both versions of the 'Experience Can't Confirm' Objection fail.

\section{The 'Experience Lacks Subjective Probability' Objection}

Let's return to Davidson's response to McDowell's view that experience has propositional content, i.e. the denial of premise 3 of the argument of section 2.1. Instead of explaining why experience lacks content, Davidson sketches what he calls an 'additional puzzle' for proponents of Experiential Foundationalism who think experience has content. He writes:

I do not see how the (propositional) content one takes in [in perception] can be evidence for a belief, since it does not, in itself, have any subjective probability (if it did, it would be a belief). How can an attitude that assigns no probability to a proposition convey a probability (positive or negative) to, or provide evidence for, a belief? ${ }^{11}$

\footnotetext{
11 "Reply to Roger F. Gibson," in ed. Urszula M. Zeglen, Donald Davidson: Truth, Meaning, and Knowledge (New York: Routledge, 1999), 135.
} 
Let me make three preliminary observations about the line of thought here, before I assess it.

First, one might think Davidson unnecessarily limits his target. After all, some experiential foundationalists do not think of experience as evidence for a belief but nevertheless as something that, in the right conditions, can justify a belief. Fortunately, Davidson can alter his argument easily enough to avoid this worry. Let's think of him, then, as offering two versions of the argument:

\section{The Justification Version}

1. Necessarily, if a belief owes its justification to some other mental state, then that other state, in itself, has a subjective probability.

2. Necessarily, an experience, in itself, has no subjective probability.

3. So, necessarily, if a belief owes its justification to some other mental state, then that other state is not an experience. $(1,2)$

The Evidence Version

1'. Necessarily, if a mental state provides evidence for a belief, then, in itself, it has a subjective probability.

2. Necessarily, an experience, in itself, has no subjective probability.

3'. So, necessarily, if a mental state provides evidence for a belief, then it is not an experience. $(1 ', 2)$

Second, in contrast with the argument of section 2.1, no premise in these arguments implies that experience lacks propositional content. Rather, Davidson's strategy is to find trouble elsewhere in the nature of experience as it contrasts with belief. Specifically, he presses the distinction between a state that has a subjective probability and one that does not. Belief falls on the first side of that line, experience on the other.

Third, while Davidson's intended target in the quoted passage is McDowell's version of Experiential Foundationalism, the argument, if it is effective against that view, is equally effective against all versions of Experiential Foundationalism. That's because experience, whether it has content or not, has no subjective probability. Thus, the real-even if unintended - target is every version of Experiential Foundationalism.

Now let's turn to an assessment of the Justification Version, specifically premise 1. Why suppose it's true? In the passage quoted above, Davidson offers what comes to this argument for it:

1a. Necessarily, if a belief owes its justification to some other mental state, that other state conveys a probability to the belief.

1b. Necessarily, if a mental state conveys a probability to a belief, that other state, in itself, has a subjective probability.

1. So, necessarily, if a belief owes its justification to some other mental state, that other state, in itself, has a subjective probability.

What should we make of this line of thought?

Let's begin with the conception of probability Davidson deploys, subjective probability. What is it? Subjective probability is, as the slogan goes, degree of belief, or, more accurately, degree of confidence. I am confident that

(a) My garage door is closed,

(b) My lawn mower will start if I pull the cord, and

(c) My university library has a copy of Aquinas's Summa Theologica.

And I am also confident that

(d) I am sitting at my desk typing,

(e) I had a meal today, and

(f) My boys are giggling hysterically in the bedroom next door, 
although I am much more confident that (d)-(f) than I am that (a)-(c). I am confident of (a)(c) to a certain degree, say, $m$; $m$ is the subjective probability that each of (a)-(c) has for me. And I am confident of each of (d)-(f) to a certain degree, say, $n$; $n$ is the subjective probability that each of (d)-(f) has for me. And $n$ is significantly greater than $m$. That is, (d)-(f) have a higher subjective probability for me than (a)-(c).

These are examples of degrees of confidence that, on a scale between 0 and 1 , are above .5. In that case, they count as beliefs. Consider, however, the degrees of confidence I have with respect to their denials; in each case, it's below .5. In that case, they count as states of disbelief. Of course, with these notions of belief and disbelief in hand, there is the theoretical option of sheer ambivalence; a degree of confidence that is posed exactly at $.5 .^{12}$

Now, my first question is this: can a state other than belief, disbelief, or ambivalence have a subjective probability? The answer is 'no'. By definition, subjective probability is degree of confidence, and degrees of confidence are, in the nomenclature of folk psychology, states of belief, disbelief, and ambivalence. With that in mind, consider the argument for premise 1 again, specifically premise 1a. Premise 1a is just the claim that

1a1. Necessarily, if a belief owes its justification to some other mental state, then that other state conveys a degree of confidence to the belief. ${ }^{13}$

Since, by definition, no state could convey a degree of confidence to a belief except a state of belief, disbelief, or ambivalence, $1 \mathrm{a} 1$ is just the claim that

1a2. Necessarily, if a belief owes its justification to some other mental state, then that other state is a state of belief, disbelief, or ambivalence and it conveys a degree (a 'subjective probability') to the belief.

And it's a short step from $1 \mathrm{a} 2$ to

1a3. Necessarily, if a belief owes its justification to some other mental state, then that other state is a state of belief, disbelief, or ambivalence.

That is, in asserting premise 1a, 1a3 is implicitly asserted. On inspection, the same goes for premise 1 itself. What should we make of the fact that $1 \mathrm{a}$ and 1 implicitly assert 1a3? So far as I can tell, 1a3 is little more that a stylistic variation on the claim that Experiential Foundationalism is false, something that Davidson was supposed to be arguing for, not implicitly asserting in one of his premises. The Justification Version, therefore, begs the question.

Perhaps the Evidence Version will fare better. Its first premise is this:

1'. Necessarily, if a mental state provides evidence for a belief, then, in itself, it has a subjective probability.

And the argument on its behalf is this:

1'a. Necessarily, if a mental state provides evidence for a belief, it conveys a probability to the belief.

1'b. Necessarily, if it conveys a probability to the belief, then, in itself, it has a subjective probability.

Unfortunately, by the argument of the last two paragraphs, mutatis mutandis, we see that both 1'a and 1' itself implicitly assert that

\footnotetext{
${ }^{12}$ Some philosophers cut the pie of confidence differently, thinking of states of belief as corresponding to degrees of confidence that exceed some threshold significantly above .5, states of disbelief as corresponding to degrees of confidence that fall below some threshold significantly below .5, and states of ambivalence as corresponding to degrees of confidence that fall inbetween these two thresholds. For my purposes, it doesn't matter how we cut the pie. What I have to say applies, mutatus mutandis, to this alternative view.

${ }^{13}$ Presumably, the probability that a state is supposed to 'convey' to a belief is subjective probability. Objective probability isn't in the picture here.
} 
1'a3. Necessarily, if a mental state provides evidence for a belief, then it is a state of belief, disbelief, or ambivalence.

But to assert this is simply to assert the denial of the central thesis of every version of Experiential Foundationalism that takes evidence possession to be essential to epistemic appraisal. One will be pardoned if one wished for a bit more in the way of an argument against the view.

\section{The 'We Can't Get Outside Our Skins' Objection}

If we squint hard enough, we can see the rudiments of another antifoundationalist argument in this passage:

We have been trying to see it this way: a person has all his beliefs about the worldthat is, all his beliefs. How can he tell if they are true, or apt to be true? Only, we have been assuming, by connecting his beliefs to the world, confronting certain of his beliefs with the deliverances of the senses one by one, or perhaps confronting the totality of his beliefs with the tribunal of experience. No such confrontation makes sense, for of course we can't get outside our skins to find out what is causing the internal happenings of which we are aware. (312)

What should we make of the argument here?

It has two prominent features. The first is the metaphor of confrontation, which hearkens back to the Vienna Circle's Moritz Schlick. ${ }^{14}$ Schlick thought that one could 'confront' the world by way of 'immediate experience' of the reality one's belief is about, and thereby 'compare' its content directly with its object in the world. When Schlick was challenged by Carl Hempel that the content of a belief can only be compared to the content of other beliefs, he offered the following illustration to the contrary:

I found, for instance, in my Baedeker the statement: 'This cathedral has two spires'. I was able to compare it with 'reality' by looking at the cathedral, and this comparison convinced me that Baedeker's assertion was true...A cathedral is not a proposition or a set of propositions, therefore I felt justified in maintaining that a proposition could be compared with reality. ${ }^{15}$

So, to carry over the analogy, by 'looking at' what one's belief is about, one can compare its content with reality. That's how one can tell that one's belief is true or apt to be true, according to Schlick.

The second prominent feature is conspicuous for its absence. Suppose one isn't able to tell whether one's beliefs are true or apt to be true. So what? Davidson doesn't say. Perhaps he'd say this: According to Experiential Foundationalism, a basic belief can owe its justification to a particular experience. But if one cannot tell, by way of that experience, whether one's basic belief is true or apt to be true, then one's basic belief cannot owe its justification to it. Thus, whether a basic belief can owe its justification to an experience depends on whether one can tell, by way of that experience, that one's basic belief is apt to be true.

Putting all this together, at the most general level, Davidson's argument, I take it, is this:

\footnotetext{
${ }^{14}$ Davidson presents the same argument in "Empirical Content," 324, where Schlick is the featured whipping-boy. There he concludes with these words: "There is, then, very good reason to conclude that there is no clear meaning to the idea of comparing our beliefs with reality or confronting our hypotheses with observations."

15 "Facts and Propositions" (1934-35), reprinted in eds. Roderick Chisholm and Robert Swartz, Empirical Knowledge (Englewood Cliffs, New Jersey: Prentice-Hall, 1973), 66.
} 
1. Necessarily, one's basic belief, B, can owe its justification to an experience, $\mathrm{E}$, only if one can 'confront' the world, by way of $\mathrm{E}$, and thereby 'compare' the content of B with the world.

2. Necessarily, one cannot 'confront' the world, by way of E, and thereby 'compare' the content of B with the world.

3. So, one's basic belief cannot owe its justification to an experience. $(1,2)$ And in defense of premise 1, we have this argument:

1a. Necessarily, one's basic belief, B, can owe its justification to an experience, $\mathrm{E}$, only if one can tell, by way of $\mathrm{E}$, whether B is true or apt to be true.

1b. Necessarily, one can tell, by way of E, whether B is true or apt to be true only if one can 'confront' the world, by way of $\mathrm{E}$, and thereby 'compare' the content of B with the world.

1. So, necessarily, one's basic belief, B, can owe its justification to an experience, E, only if one can 'confront' the world, by way of $\mathrm{E}$, and thereby 'compare' the content of B with the world. (1a,1b)

As for premise 2, Davidson has some fun, at the experiential foundationalist's expense. If you are going to use E to confront B and compare it with the world, he says, you'll have to claw your way out of your own skin! (Ouch!!) Thus, we have the following argument:

2a. Necessarily, one can confront B and compare it, by way of E, with the world only if one can get outside one's skin to find out what is causing E.

2b. Necessarily, one cannot get outside one's skin to find out what is causing E.

2. So, necessarily, one cannot 'confront' the world, by way of $\mathrm{E}$, and thereby 'compare' the content of B with the world. $(2 \mathrm{a}, 2 \mathrm{~b})$

What should we make of the main line of thought here, and its two supporting arguments?

Let's begin with the argument for premise 2 , and in particular premise 2 a. Why must one be able to 'get outside one's skin' to find out what is causing E? And, more importantly, why must one be able to find out what is causing E in the first place? Davidson doesn't say.

Perhaps we can fill in the blanks for him. As for the second question, maybe the idea is this. One must be able to find out what is causing $\mathrm{E}$ because otherwise one cannot rely on $\mathrm{E}$ to compare the content of $\mathrm{B}$ with the world. For one can thus rely on $\mathrm{E}$ only if $\mathrm{E}$ is an experience of the world; and $\mathrm{E}$ is an experience of the world only if there is a causal connection between the relevant bit of the world and E. But if one could not tell what that bit was, then one could not tell whether there is a causal connection between it and $\mathrm{E}$, and hence one could not tell whether E was trustworthy, in which case one could not rely on E to make the needed comparison.

As for the first question, consider the alternative: finding out the cause of $\mathrm{E}$ while remaining in your skin. How might you do that? Well, you might ask somebody, or you could double-check for yourself. Of course, Davidson won't deny that you can find out the cause of $\mathrm{E}$ in these ways. He's no skeptic. He will deny, however, that in that case you have confronted the world, by way of $E$, and thereby compared the content of B with it. For in that case you have used some other combination of experiences and beliefs to do the job, and whether some other combination of experiences could do the job was never at issue. What is at issue is whether by way of $E$ you can confront the world and compare the content of B with it. Neither asking or double-checking addresses that issue.

This is the best I can do in the way of defending premise 2. I now turn to premise 1.

The premises of the argument for premise 1 are ambiguous. Davidson's central term'tell' - can be taken to mean what we commonly mean by 'distinguish,' 'discriminate,' and 'differentiate,' as in 'He could not tell whether it was a cedar or a fir,' or 'It wasn't until she 
turned the lights on that she could tell that it wasn't her husband after all.' Alternatively, it can be taken to mean what we commonly mean by 'show' or 'inform,' as in 'Tell me why you think that,' or 'He finally told me the argument he'd been working on all summer,' or 'She didn't have to say a word; her tears told me everything.' Consequently, Davidson's argument for premise 1 is ambiguous between two different versions. I'm not sure which he has in mind, although I'd bet it's one of these two. Let's examine each, beginning with the show-version.

\subsection{The show-version of Davidson's argument for premise 1}

The show-version goes like this:

1as. Necessarily, one's basic belief, B, can owe its justification to an experience, $\mathrm{E}$, only if one can show, by way of $\mathrm{E}$, that $\mathrm{B}$ is true or apt to be true.

1bs. Necessarily, one can show, by way of E, that B is true or apt to be true only if one can 'confront' B and 'compare' it, by way of E, with the world.

1. So, necessarily, one's basic belief, B, can owe its justification to an experience, E, only if one can 'confront' B and 'compare' it, by way of E, with the world. (1as, $1 \mathrm{bs})$

I think both premises of the show-version are arguably false.

Premise $1 \mathrm{bs}$ is false since there are other ways in which one can show, by way of E, that B is true or apt to be true (if one can show such a thing at all). If you were to challenge me to show you, by way of E, that B is true, or apt to be true, I would respond like this: 'Well, E occurred; and B is apt to be true if E occurs; so, B is apt to be true.' If I could show that the premises of this argument were true or apt to be true, couldn't I then show, by way of $E$, that $\mathrm{B}$ is apt to be true? It certainly seems so. But then I don't have to be able to confront-andcompare in order to show, by way of $\mathrm{E}$, that $\mathrm{B}$ is true, or apt to be true-contrary to premise 1 bs.

Davidson might insist that in the sort of case that I am imagining, my belief B would not be basic. For by giving the argument, my belief would owe its justification to it and not to my experience.

But this response fails for two reasons. First, it fails to distinguish an ability from its exercise. In the case I described, I did not give the argument; so it can't be that, in that case, $b y$ giving the argument, my belief B owes its justification to it. Rather, I was able to give it, or I could have given it if you had challenged me. My ability to give the argument is enough to make it the case that I can show, by way of E, that B is true or apt to be true. Second, and more importantly, the suggested response is a non-sequitur. Even if I gave the argument, it doesn't follow that my belief B would owe its justification to it rather than my experience. For, on the one hand, an experientially justified belief can owe its justification, in part, to an argument, provided that it would be justified by the experience even if it owed no justification to that argument. (See note 1, above.) On the other hand, just because I gave an argument which would justify a belief of mine, it does not follow that it is my grounds for the belief, even in part. Suppose I'm looking, in broad daylight, at a mug on my study desk; you come in and give a stellar argument to the best available explanation for there being a mug on my desk. I endorse its premises enthusiastically, and even agree that the conclusion follows, but the argument doesn't thereby become my grounds for my belief, not even in part.

Premise 1as is also false; but before I explain why, I want to expose a fallacious piece of reasoning for it. And to do that, I need to make two preliminary remarks. First, we must distinguish a person's justifying something from its being justified. This distinction applies to 
justification generally, not just epistemic justification. Consider moral justification, for the sake of illustration. When one justifies her behavior from a moral point of view, she brings to light a fact that was already the case, namely that it was justified. Similarly, when one justifies her belief from an epistemic point of view, she brings to light a property that it had prior to engaging in that activity, namely the property of being justified (or whatever that property supervenes on). Let's call this general distinction the show-be distinction, 'show' for the activity of justifying and 'be' for the property of being justified. ${ }^{16}$ Second, when one justifies one's belief one states one's grounds for it and then argues on the basis of other things one believes that those grounds make one's belief true or apt to be true.

With these two remarks under our belts, we can see why the following piece of reasoning for premise las is fallacious:

Your basic belief B can owe its justification to an experience, E, only if you can show, by way of $E$, that B is true or apt to be true because otherwise you would not be able to justify B, by way of E. After all, what if someone challenged your belief that B? What would you have to say then? You'd have to cite your grounds for believing $\mathrm{B}$, namely your experience $\mathrm{E}$, and then argue from things you already believe that $\mathrm{B}$ is true or apt to be true given E. And that's tantamount to showing, or at least trying to show, by way of $\mathrm{E}$, that B is true or apt to be true-which is what premise las says you have to do.

This is fallacious because although you would have to be able to argue successfully that B is true or apt to be true given $\mathrm{E}$ if you were to justify $B$, by way of $\mathrm{E}$, that is not what premise las is about. It is about $B$ 's being justified, by way of E. We cannot just assume, without argument, that one's belief is justified only if one can meet a challenge to show that one's belief is justified.

So what's the argument? One thing we can sure of is this: we won't find it in Davidson's writings. Instead of rehearsing some options, ${ }^{17}$ let me cut to the chase and say why I suspect premise las is false. Here's my argument. I begin with three claims. First, las is true only if the analogue for all beliefs (not just basic ones) and all grounds (not just experiences) is true. Second, if one shows that one's belief is true or apt to be true, one must have a good argument for it from the contents of other beliefs one has; and, one has such an argument only if the other beliefs whose contents one uses as premises are justified for one. Third, one's belief is justified only if it owes its justification to some grounds or other. I don't mean anything fancy by 'grounds' here. I only mean to signify whatever it is that one goes on in believing something, and I allow that sometimes what one goes on in believing something may well be its simply feeling true to one. It follows from these three claims that premise 1as is true only if, in general,

GP. Necessarily, for any of one's justified beliefs B, B is justified only if B owes its justification to some grounds $\mathrm{G}$ and one can give a good argument from beliefs one already has that B is true or apt to be true, an argument in which $\mathrm{G}$ figures crucially and whose premises one believes with justification. Sadly, GP is false. Thus, since 1as entails GP, 1 as is false. Why suppose GP is false? Here are three reasons.

\footnotetext{
${ }^{16}$ For more on the show/be distinction, see William Alston, "Internalism and Externalism in Epistemology," Epistemic Justification, 197-98.

${ }^{17}$ I count three options in Laurence BonJour, The Structure of Empirical Knowledge (Cambridge, Massachusetts: Harvard University Press, 1985). I assess their merits in "On BonJour's 'Basic Antifoundationalist Argument' and the Doctrine of the Given," Southern Journal of Philosophy (1998), 163-77.
} 
First, consider counterexamples. If one has to be able to give an argument of the required sort, then none of the mundane beliefs of those who, for one reason or another, are unable to give such arguments are justified. This consequence is implausible in the extreme. We need not think only of higher non-human animals in this connection. Consider young, normal humans, like my two-year old twins. Surely they are justified in believing on the basis of other beliefs they have that Copper, the neighbor's unusually dark yellow Labrador retriever, is coming toward them, or that the car they are getting into is the same one they got into yesterday - but they can't argue in the way $\mathrm{GP}_{2}$ requires. Or consider cases in which those who can ordinarily argue in the required way temporarily lose that capacity. Normal adults occasionally experience mental 'seizures' - episodes that render them cognitively 'tongue-tied' and which temporarily prevent them from giving arguments. The causes of such episodes are various but include shyness, insecurity, anger, shock, and the like.

Second, if GP is true, then its analogue for the moral justification of action is true as well, where one's grounds for an action are what one goes on in doing it (whether reasons or motivations):

GP'. Necessarily, for any of one's actions, A, A is morally justified only if A owes its justification to some grounds, $\mathrm{G}$, and one can give a good argument from beliefs that one already has that $\mathrm{A}$ is morally permissible, an argument in which $\mathrm{G}$ figures crucially.

But isn't GP' false? As above, consider cases in which people lack the required ability, cases in which one lacks the ability to argue altogether or to engage in moral argumentation in particular, e.g. very young children, and cases in which one temporarily loses the capacity to argue in the required way, e.g. due to science-fictional impediments or normal ones like shyness, and the like. In cases like these (and, no doubt, there are others) one's action may well be morally justified even if one is unable to give an argument of the required sort.

Third, and most importantly, GP leads to radical global skepticism, the view that no human being has any justified beliefs whatsoever. To see why, suppose that GP is true, and reflect on what actually giving such an argument requires. GP is perfectly general, so it applies to the beliefs mentioned in the consequent; moreover, it is reiterative, so it entails that, for any of one's beliefs, B, at a time t, B is justified at $t$ only if one has infinitely many other justified beliefs of a certain sort at $t$. Two worries arises. First, even if we can have infinitely many beliefs at once, we lack the cognitive capacity to have more than a handful of beliefs of the sort in question, since their content is too complex for us to grasp, to understand, even somewhat. Second, even if we were capable of grasping them, there isn't enough time to actually give the required argument. Thus, no human being can give it. So, if GP is true, no human being justifiably believes anything. ${ }^{18}$

The show-version of Davidson's argument for premise 1 of the 'We Can't Get Outside Our Skins' Objection fails. I turn now to the discrimination-version.

\subsection{The discrimination version of Davidson's argument for premise 1}

The argument is this:

\footnotetext{
${ }^{18}$ For more on higher-level requirements of a sort represented by GP, see Alston, "Higher Level Requirements for Epistemic Justification," in eds. Keith Lehrer and Ernest Sosa, The Opened Curtain (Boulder, Colorado: Westview Press, 1991), as well as "Two Types of Foundationalism," "Level Confusions in Epistemology," and "An Internalist Externalism," all in Epistemic Justification.
} 
1ad. Necessarily, one's basic belief, B, can owe its justification to an experience, $\mathrm{E}$, only if one can discriminate, by way of $\mathrm{E}$, whether $\mathrm{B}$ is true or apt to be true.

1bd. Necessarily, one can discriminate, by way of $\mathrm{E}$, whether $\mathrm{B}$ is true or apt to be true only if one can 'confront' the world, by way of E, and thereby 'compare' the content of B with the world.

1. So, necessarily, one's basic belief, B, can owe its justification to an experience, E, only if one can 'confront' the world, by way of E, and thereby 'compare' the content of B with the world. (1ad,1bd)

What should we make of this argument?

One might deny premise 1ad on the grounds that a purely deontological conception of justification implies its denial (see section 2.1). But let's suppose, for the sake of argument, that such a conception is incorrect; indeed, let's suppose that 1ad is true. I want to focus on premise $1 \mathrm{bd}$.

Here we must insist that experience certainly does permit us to navigate our immediate environment; moreover, it could not do so unless it enabled us to discriminate between different things or states of affairs in the world, and hence between truths and falsehoods. That is, the antecedent of $1 \mathrm{bd}$ is true. In that case, Davidson is in a bit of a pickle. According to him, confronting-and-comparing by way of experience does not 'make sense': "for," as he picturesquely puts it, "we can't get outside our skins to find out what is causing the internal happenings of which we are aware". So, according to Davidson, the consequent of $1 \mathrm{bd}$ is false - in which case $1 \mathrm{bd}$ is false.

Davidson can save the argument for premise 1 in one of two ways. First, he can retract what he said about confronting-and-comparing. Unfortunately, the claim that one can 'confront' the world, by way of E, and thereby 'compare' the content of B with the world is the denial of premise 2 of his main argument (see page xxx above). Second, he can say that we are wrong to think that, by way of experience, we can discriminate between different things or states of affairs in the world. You look to your right and you have an experience as of seeing a mug; you grasp it and you have an experience as of holding a ceramic handle; you take a sip and you have an experience as of tasting coffee. That's all well and good. But your visual experience did not enable you to discriminate between a mug and an airliner, your tactile experience did not enable you to discriminate between the handle of a mug and a living blackberry vine, and your gustatory experience did not enable you to discriminate between coffee and isopropyl alcohol. This way lies global perceptual skepticism.

I conclude that the discrimination-version of the argument fails: $1 \mathrm{bd}$ is false. Perhaps there are other arguments for premise 1 that avoid the objections to Davidson's argument for it. If so, I am unware of them.

\section{The 'Information Delivery' Objection}

Immediately following the passage that contains the objection we have just examined, we find these words:

Introducing intermediate steps or entities into the causal chain, like sensations or observations, serves only to make the epistemological problem more obvious. For if the intermediaries are merely causes, they don't justify the beliefs they cause, while if they deliver information, they may be lying. The moral is obvious. Since we can't swear intermediaries to truthfulness, we should allow no intermediaries between our 
beliefs and their objects in the world. Of course there are causal intermediaries. What we must guard against are epistemic intermediaries. (312)

We might see these words as embellishing or furthering the argument of the passage that immediately precedes it and which we assessed in the last section, but we might also see them as expressing a different argument, one that emphasizes the contemporary theme of information processing and delivery rather than the comparatively old-fashioned verificationist theme of confronting-and-comparing. Suppose we take the latter course. In that case, how does the argument go exactly?

Davidson means to offer a dilemma, and he means to contrast merely causing, on the one hand, and delivering information, on the other. A mere cause is something that is unable to deliver information. Thus, the argument can be fairly put like this:

1. Necessarily, either an experience delivers information or it does not.

2. Necessarily, if it does, then we must swear it to truthfulness.

3. Necessarily, if it does not, then it does not justify a belief.

4. So, necessarily, either an experience does not justify a belief or we must swear it to truthfulness. (1-3)

5. Necessarily, we cannot swear it to truthfulness.

6. So, an experience cannot justify a belief. $(4,5)$

While many epistemologists would deny premise 5 - on the grounds that experience, in general, is reliable, and thus that every experience enjoys a presumption of truthfulness - I won't take that route. My interest is in the curious premise 2, and Davidson's argument for it.

His argument is this: if an experience delivers information, it may be lying, and if it might be lying, then we must swear it to truthfulness. Of course, these are metaphors. An experience cannot 'lie', nor can it take an oath. But what, exactly, are these metaphors meant to express? Presumably this: if an experience can deliver information, then it might present or represent things inaccurately; and, if an experience is able to present or represent things inaccurately, then we must see to it that the information it delivers is true, or apt to be true-which, at a minimum, involves believing, with justification, that this is so. With these less metaphorical readings in mind, premise 2 and the argument for it can be more clearly seen as follows:

2a. Necessarily, if an experience delivers information, then it can present or represent things inaccurately.

2b. Necessarily, if it can present or represent things inaccurately, we must believe, with justification, that the information it delivers is true, or apt to be true.

2. So, necessarily, if an experience delivers information, then we must believe, with justification, that the information it delivers is true, or apt to be true.

What should we make of this argument for premise 2?

I am puzzled by 2a. I see no necessary connection between an experience's capacity to deliver information and its capacity to present or represent things inaccurately. To be sure, given the actual defects in our cognitive construction, for any type of perceptual experience we enjoy, there is some way a token of that type can present or represent things inaccurately. But this does not follow from the capacity of experience to deliver information. It follows from the aforementioned defects.

My main worry, however, is premise $2 \mathrm{~b}$. Why suppose that if an experience can present or represent things inaccurately, then we must believe, with justification, that the information it delivers is true, or apt to be true. So far as I can see, the only relevant answer is that, if we didn't, then no experience could justify a belief. That is, if $2 b$ is true, it's also true that 
- $\quad$ One's belief, B, can owe its justification to an experience, E, only if one believes with justification that the information E delivers is true, or apt to be true.

And here we see a familiar claim, one sufficiently like GP (see section 4.1) that we need not repeat the reasons for denying it.

Even if premises $2 \mathrm{a}$ and $2 \mathrm{~b}$ are false, premise 2 might still be true. Is there any reason to think it is false? Suppose I look at the mug on my desk in propitious conditions and form the belief that there sits a mug. Presumably, if experience delivers information at all, then my visual experience delivered the information that there sits a mug, as encoded in the content of my belief. So far so good. But now suppose that you learn that I lack the further belief that the information that my visual experience delivers is apt to be true. I don't believe it's false that the information thus delivered is apt to be true. Nor do I have any reason to think that the information is mistaken or that the relevant delivery system is inauspicious. I simply haven't formed an opinion about the matter; I'm too busy doing other things to be so inanely selfreflective. But then, it is not the case that I believe, with justification, that the information my visual experience delivers is apt to be true. Should you, upon learning these things, infer that my experience did not deliver the relevant information? Indeed, since I wouldn't believe that there sits a mug unless my experience did deliver that information, should you, upon learning these things, infer that I really don't even believe that there sits a mug? At the very least, it is dubious whether you should infer these things; consequently, at best, premise 2 is dubious.

\section{The 'Reference to What We Already Accept' Objection}

The following passage might be seen as containing the seed of an argument against Experiential Foundationalism:

What distinguishes a coherence theory is simply the claim that nothing can count as a reason for holding a belief except another belief. Its partisan rejects as unintelligible the request for a ground or source of justification of another ilk. As Rorty has put it, 'nothing counts as justification unless by reference to what we already accept, and there is no way to get outside our beliefs and our language so as to find some test other than coherence.' (Mirror, 178) About this I am...in agreement with Rorty. (310)

There are several things we might object to here, but that would only detain us from getting to the argument lurking in the platitude that "nothing counts as justification unless by reference to what we already accept". The argument, I take it, is this:

1. Necessarily, for any of one's beliefs, B, something counts as justification for B only by reference to one's other beliefs.

2. Necessarily, if something counts as justification for B only by reference to one's other beliefs, then it isn't basic.

3. Necessarily, if B isn't basic, then it does not owe its justification to experience.

4. So, for any of one's beliefs, B, it does not owe its justification to experience. (1-3)

Thus, an experience cannot justify a belief; so Experiential Foundationalism is false. What should we make of this argument?

Premise 3 is true by definition of 'basic'. And premise 1 is also true, since something counts as justification for B only if one is blamelessly unaware of any defeaters for it in one's stock of beliefs. Thus, any statement of the conditions for justification must make reference to one's other beliefs. But why suppose that premise 2 is true? 
Presumably because, if the conditions under which B is justified makes reference to one's other beliefs, B will owe its justification to those other beliefs, in which case B isn't basic. Regrettably, this is false, as is premise 2 itself. To see why, let's distinguish two ways in which the conditions under which a belief is justified can make reference to other beliefs, a positive way and a negative way:

P. One's belief, B, is justified only if one believes that....

N. One's belief, B, is justified only if it is false that one believes that....

In both cases, reference is made to one's other beliefs. P says that a certain sort of belief must be in one's stock of beliefs; $\mathrm{N}$ says that there must not be a certain sort of belief in one's stock of beliefs. Only P, however, can be seen as providing a reason for premise 2 since $\mathrm{N}$ does not require that there be anything in the stock of one's beliefs from which one's belief, $\mathrm{B}$, derives its justification, even in part. Thus, the conditions under which $\mathrm{B}$ is justified can make reference to one's other beliefs - in the way recommended by $\mathrm{N}$ - even if $\mathrm{B}$ does not owe its justification to them, and even if B is basic.

\section{The 'He Can't Say It' Objection}

Consider the following passage:

Emphasis on sensation or perception in matters epistemological springs from the obvious thought: sensations are what connect the world and our beliefs, and they are candidates for justifiers because we often are aware of them. The trouble we have been running into is that the justification seems to depend on the awareness, which is just another belief.

Let us try a bolder tack. Suppose we say that sensations themselves, verbalized or not, justify certain beliefs that go beyond what is given in sensation. So, under certain conditions, having the sensation of seeing a green light flashing may justify the belief that a green light is flashing. The problem is to see how the sensation justifies the belief. Of course if someone has the sensation of seeing a green light flashing, it is likely, under certain circumstances, that a green light is flashing. We can say this, since we know of his sensation, but he can't say it, since we are supposing he is justified without having to depend on believing he has the sensation. Suppose he believed he didn't have the sensation. Would the sensation still justify him in the belief in an objective flashing green light? (311)

What, exactly, is the argument here?

\subsection{The belief-that-he-has-the-experience version}

On the face of it, the idea seems to be this. Suppose someone has 'a belief in an objective flashing green light' and suppose that the experiential foundationalist says that this belief owes its justification to this person's 'sensation of seeing a green light flashing'. Unlike us, this person 'can't say' that, in general, "if someone has the sensation of seeing a green light flashing, it is likely, under certain circumstances, that a green light is flashing;" for if he were to 'say it,' his belief would 'depend' for its justification on the further belief that 'he has the sensation'. In that case, his belief in a flashing green light owes its justification to his belief that he has the sensation-so it can hardly be basic.

But what if he does not believe that he has the sensation? What if he 'believed he didn't have the sensation,' or what if he lacked any belief about the matter at all? As for the first sort of case, Davidson asks, "[w]ould the sensation still justify him in the belief in an objective flashing green light?" Of course, coming from Davidson, the question is purely rhetori- 
cal: the sensation would not justify the person's belief in a flashing green light if he believed he didn't have it. Why is that? Davidson doesn't say. But let's suppose he's right. That still leaves open the possibility mentioned above, that the man had no belief about his sensation at all, and it is not a mere possibility. We form beliefs about 'the sensation of seeing a green light flashing' and its ilk very, very rarely. What does Davidson have to say about this ubiquitous sort of case? Nothing. Or rather, nothing explicit. Fortunately, we can fill out the argument using something else he explicitly says, in the first paragraph of the quote above. There he says that sensations are "candidates for justifiers because we often are aware of them". This suggests that, according to Davidson, a sensation can justify a belief only if one is aware of it. Now add his statement, in the same paragraph, that "the awareness [of a sensation] is just another belief," and it follows that if the man lacks the belief that he has the sensation, then his belief in a flashing green light is not justified on the basis of the sensation. $^{19}$

How shall we reconstruct the extended line of thought here, recalling that Davidson means to target Experiential Foundationalism per se, not just sensation theories? We can put it like this:

1. Necessarily, if one has a belief, B, that owes its justification to an experience, $\mathrm{E}$, then either one has the further belief, B', that one has E, or one does not have B'.

2. Necessarily, if one has B', then the justification of B depends on B'.

3. Necessarily, if the justification of B depends on B', then B is not basic.

4. So, necessarily, if one has B', then B is not basic. $(2,3)$

5. Necessarily, if one does not have B', then one is unaware of one's grounds for B.

6. Necessarily, if one is unaware of one's grounds for B, then B is not justified.

7. Necessarily, if B is not justified, then one's belief is not basic.

8. So, necessarily, if one does not have B', then B is not basic. (5-7)

9. So, necessarily, if one has a belief, $B$, that owes it justification to an experience, $\mathrm{E}$, then $\mathrm{B}$ is not basic $(1,4,8)$.

What should we make of this argument?

Premise 3 is false. For the justification of a basic belief can depend on some other beliefs and yet still be basic, so long as it would still be justified even if it did not owe any of its justification to them. This is just a consequence of the fact that a belief's justification can have multiple sources. (See note 1.) Let's say that if the justification of a belief B depends on further beliefs and it would not be justified if it were not thus dependent, then the justification of B depends in large part on those further beliefs. In that case, although premise 3 is false, it is true that

3'. Necessarily, if the justification of one's belief, B, depends, in large part, on that further belief, B', then B is not basic.

What should we make of premise 6 ? Consider it, first, in light of a purely truth-conducive conception of epistemic justification, according to which (roughly) justification is a matter of believing in a way that is likely to get one to the truth. We might insist that one must also be blamelessly unaware of any defeaters. But, once we make that addition, why, from the point of view of a purely truth-conducive conception, should we add that the believer must be aware of her grounds? If there is a plausible answer to this question, it will not be rooted in a purely truth-conducive conception of justification.

\footnotetext{
${ }^{19}$ My reading parallels that of Davidson's symapthetic commentator, Simon Evnine, Donald Davidson (Stanford, California: Stanford University Press, 1991), 138-39.
} 
So, what about a conception of justification that includes a deontological component, one according to which justification is, at least in part, a matter of believing in such a way that one does not violate any of one's epistemic duties? Does it lend support to premise 6? If so, it will be because we have an epistemic duty to the effect Do not believe something unless you are aware of your grounds for believing it. But if this is a duty of ours, our everyday beliefs are rarely justified-we simply are not aware of our grounds very often, mostly because we don't take the time to be self-reflective in this way.

Suppose we back off awareness to something like accessibility - what's required for justification is not that one be aware of one's grounds but rather that one could become aware of one's grounds, on reflection. This is more plausible, much more plausible. Could Davidson take advantage of it? Well, if so, he'd have to modify the relevant portion of the argument like this:

5'. Necessarily, if one does not have B', then one could not become aware of one's grounds for B.

6'. Necessarily, if one could not become aware of one's grounds for B, then B is not justified.

7. Necessarily, if B is not justified, then one's belief is not basic.

8. So, necessarily, if one does not have B', then B is not basic. (6-9)

The trouble here, however, is that $5^{\prime}$ is false. One could become aware of one's grounds even if one in fact has no beliefs about them at all.

Above, we saw that, strictly speaking, premise 3 is false, unless we modify it like this:

3'. Necessarily, if the justification of one's belief, B, depends, in large part, on that further belief, B', then B is not basic.

To preserve the validity of the argument, we must then modify premise 2 :

2'. Necessarily, if one has B', then the justification of B depends, in large part, on B'.

What should we make of 2'?

Note that $\mathrm{B}^{\prime}$ is a belief with a particular sort of content, a belief that one has an experience. It is arbitrary, however, to restrict the condition 2' lays down to beliefs with that content. If it applies to them, it also applies to beliefs that one has some other sort of grounds, say, another belief. That is, if 2' is true, then, in general, it is true that

2*. Necessarily, (if one has some belief, B, that owes its justification to some grounds $\mathrm{G}$, then) if one has the further belief, $\mathrm{B}^{*}$, that one has $\mathrm{G}$, then the justification of $\mathrm{B}$ depends, in large part, on $\mathrm{B}^{*}$.

What should we make of $2 *$ ?

Consider the following case. I just came to believe that my wife turned on the ignition to her car. Suppose my belief, call it ' $\mathrm{B}_{1}$ ', is justified and suppose that it is justified on the basis of an inference from another belief of mine, say my conjunctive belief that it sounds like her car started and if it started, it's quite likely that she turned on the ignition. This latter belief, call it ' $\mathrm{G}_{1}$ ', is my grounds for $\mathrm{B}_{1}$. It is what I go on in coming to believe that she turned on the ignition. Suppose I'm in a self-reflective mood, and I form the further belief, $\mathrm{B}_{2}$, that I have $G_{1}$, that is, suppose that I form the further belief that I have the belief that it sounds like her car started and if it started, it's quite likely that she turned on the ignition. If $3 *$ is true, then the justification of $\mathrm{B}_{1}$ depends, in large part, on my having $\mathrm{B}_{2}$. But is this consequence correct? That all depends. It depends on whether if $\mathrm{B}_{1}$ were to owe no part of its justification to $\mathrm{B}_{2}$, and nothing were substituted in its stead, then it would not be justified. If so, then the consequence is correct; if not, then it's incorrect. So, suppose I had not been self-reflective in the way I described; suppose, instead, that I had not formed the further belief $\mathrm{B}_{2}$; and sup- 
pose nothing were substituted in its stead. Would $\mathrm{B}_{1}$ fail in that case to be justified? Davidson will insist that it would so fail, and his rationale for this verdict is that $\mathrm{B}_{1}$ is justified only if I am aware of my grounds. But, as we've seen, that way lies rampant skepticism. So we will need some other rationale for insisting that if $I$ had not formed $B_{2}, B_{1}$ would not have been justified.

Here's a suggestion: I don't have to form $\mathrm{B}_{2}$ in order for $\mathrm{B}_{1}$ to be justified; but given that I did, the justification of $\mathrm{B}_{1}$ depends on it. That is, although (contra Davidson) one's belief can be justified without an awareness of one's ground, one's belief cannot be justified while one is aware of one's grounds without the justification of one's belief depending, in large part, on that awareness. Davidson can defend 2 ' and $2^{*}$ with this much weaker claim, which lacks the skeptical implications of his actual rationale.

What should we make of this suggestion? First, note that it is compatible with Experiential Foundationalism. That is, even if an experience cannot justify a belief when one has the further belief that one has the experience, it doesn't follow that an experience cannot justify a belief. That follows only if one must have the further belief (awareness) that one has the experience in order for one's belief to be justified, which is just Davidson's skepticisminducing rationale (which we've rejected). Second, once we separate premise 2' and 2* from Davidson's skepticism-inducing rationale, and then reject the latter, we are left without a reason to endorse 2 ' or $2 *$. The suggestion under discussion is instructive on this score. It bids us to divide the cases into two groups, those in which we are not aware of our grounds and those in which we are. Of the former, it is silent as to whether its members can owe their justification to experience; of the latter, it exclaims that they cannot. But why? Why does this epistemic difference attend this particular psychological difference? There appears to be no answer, short of reverting to Davidson's skepticism-inducing rationale. Thus, shorn of that rationale, neither 2' nor $2^{*}$ can get off the ground.

\subsection{The concept-possession belief version}

Let's step back and take a look at the big picture. The thrust of Davidson's 'He Can't Say It' Objection is that an experience can justify a belief only if there is some further belief that one must have, and without which one's belief is not justified. The trouble we have been running into is that Davidson's candidate - the further belief that one has the experience - is one that we rarely have, with the result that few mundane beliefs are justified. What Davidson needs, then, is a sort of belief that is ubiquitous and thereby avoids skeptical implications.

Here's a candidate. When one forms a belief, even the most mundane belief, one applies at least one concept. But one cannot apply a concept unless one has a grasp of it, at least somewhat. And for one to have a grasp of a concept, even somewhat, is for one to be able to discriminate between things to which it applies and things to which it does not apply. A disposition to perfect application is, of course, unnecessary; but, at least for a variety of things that do and do not fall under the concept, one must be disposed to apply it correctly. Now, this capacity to discriminate consists in, among other things, the possession of certain beliefs: non-occurrent beliefs (say, expectations) about how things that fall under the concept would tend to behave under various conditions, for example; as well as non-occurrent beliefs about the concept's interrelations with other concepts.

Davidson's purposes may be well served by such concept-possession beliefs, as we might call them. For if belief requires concept-application, and concept-application requires conceptpossession beliefs, then one cannot have a belief without having further concept-possession be- 
liefs. Consequently, such concept-possession beliefs are as ubiquitous as any sort of belief can be. The skeptical implications of Davidson's candidate for a further belief are thereby avoided.

A Davidson-style 'He Can't Say It' Objection based on our new candidate would go like this:

1. Necessarily, if one has a belief, B, that owes it justification to some experience, $\mathrm{E}$, then either one has further, relevant concept-possession beliefs or one does not.

2. Necessarily, if one has further, relevant concept-possession beliefs, then the justification of B depends in large part on them.

3. Necessarily, if the justification of B depends in large part on them, then it's false that B is basic.

4. So, necessarily, if one has further, relevant concept-possession beliefs, then it's false that B is basic. $(2,3)$

5. Necessarily, if one does not have further, relevant concept-possession beliefs, then one does not have B.

6. Necessarily, if one does not have B, then it's false that B is basic.

7. So, necessarily, if one does not have further, relevant concept-possession beliefs, then it's false that B is basic. $(5,6)$

8. So, necessarily, if one has a belief, $\mathrm{B}$, that owes it justification to an experience, $\mathrm{E}$, then it is false that $\mathrm{B}$ is basic $(1,4,7)$.

This version of the argument avoids all of the objections I brought against Davidson's version. Nevertheless, premise 2 is not just obvious; we must ask what reason there is to endorse it.

Here is a suggestion:

2a. If one has a belief, B, that owes its justification to some grounds, $\mathrm{G}$, then if one could not even have B unless one also had some further, relevant conceptpossession beliefs, B owes its justification in large part to them.

2b. One could not have B unless one also had some further, relevant conceptpossession beliefs.

Premise 2 follows. However, $2 \mathrm{a}$ is false. For, $2 \mathrm{a}$ confuses what it is that a belief owes its justification to with what it is that a belief owes its existence to. All manner of things are such that without them, one's belief, B, could not exist. It does not follow that B owes its justification to them, even in part. Thus, the mere having of some further, relevant belief - even a concept-possession belief - without which one would not have the target belief, does not suffice for the latter's owing its justification to the former, even in part. ${ }^{20}$ Call this objection the existence/justification objection. Can premise 2 be defended whilst avoiding this objection?

One might think so. After all, what if one could not have a belief without having some further, relevant concept-possession beliefs that were justified? In this connection, note that it is very difficult to see how one could have the concepts necessary to form a belief without the relevant concept-possession beliefs being justified for one. Having a concept-i.e. having a grasp of it, even somewhat-implies knowing how to use it. But if one has no justified nonoccurrent beliefs (e.g., expectations) about the conditions of its correct application or its relations with other concepts, one does not know how to use it. Thus, we might reformulate the argument for premise 2 like this:

2a'. If one has a belief, B, that owes its justification to some grounds, $G$, then if one could not even have B unless one also had some further, relevant concept-

\footnotetext{
${ }^{20}$ Alston draws this distinction in "What's Wrong With Immediate Knowledge," Epistemic Justification, 63-4.
} 
possession beliefs that are justified, B owes its justification in large part to them.

2b'. One could not have B unless one also had some further, relevant conceptpossession beliefs that are justified.

Premise 2 follows.

This would be an advance if it weren't for the fact that premise 2a' does not avoid the existence/justification objection. It may well be that a logically necessary condition for having a belief, $\mathrm{B}$, is that one have further, relevant and justified concept-possession beliefs; but it simply does not follow that B's justification is at all derived from the justification of those further beliefs.

Perhaps what is needed to secure premise 2 is this:

$2 \mathrm{a}$ ', If one has a belief, $\mathrm{B}$, that owes its justification to some grounds, $\mathrm{G}$, then if $B$ could not be justified unless one also had some further, relevant conceptpossession beliefs that are justified, B owes its justification in large part to them.

2b'?. B could not be justified unless one also had some further, relevant conceptpossession beliefs that are justified.

Premise 2 follows.

Unfortunately, 2a" runs afoul of the existence/justification objection. For even if it is absolutely impossible that one have B while B is justified and yet lack some further, relevant concept-possession beliefs that are justified, it does not follow that B's justification, as opposed to B's existence, derives from the justification of those further beliefs.

By now, it should be fairly clear what sort of thing we must say if we are to secure premise 2 whilst avoiding the existence/justification objection. We must say something like this:

$2 \mathrm{a}$ "'. If one has a belief, $\mathrm{B}$, that owes its justification to some grounds, $\mathrm{G}$, then if $\mathrm{B}$ could not be justified unless one also had some further, relevant conceptpossession beliefs that are justified and to which B owes its justification in large part, B owes its justification in large part to them.

$2 \mathrm{~b}$ ', . B could not be justified unless one also had some further, relevant conceptpossession beliefs that are justified and to which $B$ owes its justification in large part.

Premise 2 follows; and 2a", certainly avoids the existence/justification objection. But the sad truth is that $2 \mathrm{~b}$ "' is merely a stylistic variation on an explicit denial of Experiential Foundationalism.

I see no plausible way to defend premise 2 without either begging the question or running afoul of the existence/justification objection.

\section{Conclusion}

In this paper, I have assessed several arguments against Experiential Foundationalism that I have found in —or, at any rate, have been inspired by_Davidson's writings. Each of them fails. It is important to note, however, that each of them fails for reasons that can be endorsed - indeed, I would say should be endorsed - by antifoundationalists and foundationalists alike. Every reason that I have put forward is perfectly at home with any antifoundationalist theory you like. All that follows is that if we wish to reject Experiential Foundationalism sensibly, we will be severely 
disappointed if we look to one of the most influential and widely respected philosophers of our century, Donald Davidson. ${ }^{21}$

\footnotetext{
${ }^{21}$ For comments on earlier drafts of this paper, I thank Tom Downing, John Hawthorne, Christian Lee, Ned Markosian, Phil Montague, Mike Murray, Paul Olscamp, and, especially, Stuart Brock, Frances Howard-Snyder, and Hud Hudson. But most of all, I thank William Alston, on whose work I have relied heavily in these pages, as anyone who knows that work will already have recognized. I am also grateful to him for comments on the penultimate draft of this paper. Initial work was done while I was a participant in a seminar at Calvin College, Summer 1999, and while I was a fellow at the Center for the Philosophy of Religion, University of Notre Dame, 1999-2000. I am grateful to these institutions for their support. I also benefited from discussion at the Society of Christian Philosophers Pacific Division Meeting, March 2000.
} 